\title{
Groundwater Assessment through an Integrated Approach Using GIS and Electrical Resistivity Technique: A Case Study from the Bullom Group of Sediments in Sierra Leone
}

\author{
Yaguba Jalloh ${ }^{1,2^{\star}}$, Mustapha Olajiday Thomsa ${ }^{1}$ and Kyuro Sasaki ${ }^{2}$ \\ ${ }^{1}$ Department of Geology, Fourah Bay College, University of Sierra Leone, Freetown, Sierra Leone \\ ${ }^{2}$ Department of Earth Resources Engineering, Kyushu University, Fukuoka, Japan
}

\begin{abstract}
Electrical Resistivity in conjunction with Geographic Information System (GIS) techniques have been widely used in groundwater resource management. In this research, Vertical Electric Sounding (VES), an Electrical Resistivity method, was integrated with GIS to delineate geo-electric characteristics and evaluate groundwater potential of the Bullom group of sediments in Sierra Leone. For this assessment, a total of 5 vertical electrical sounding stations were established within the site. The Schlumberger electrode configuration and the expanding procedure were used for data acquisition. The VES curves generated were interpreted using partial curve matching. The depth sounding interpretation results were used to generate geo-electric sections from which the aquifer was delineated. The aquifer revealed four subsurface layers which comprises of sandy topsoil, clayey sand which acts as aquitard and sandy gravel (confine aquifer) that serves as a source of portable water in the study area. A GIS model was then developed to locate the suitable groundwater prospective zones which reveals the average depth to groundwater to be between $10 \mathrm{~m}$ to $30 \mathrm{~m}$. This research concluded that the boreholes were sited in high conductivity zones in VES layers 1, 2, 3 and 4 as they contain probable aquifers with good yield.
\end{abstract}

Keywords: Vertical electric sounding; Bullom group of sediments; Groundwater assessment; GIS

\section{Introduction}

Geophysical survey is very important for both groundwater resource mapping and water quality evaluations [1]. The occurrence and movement of groundwater are controlled mainly by porosity and permeability of the surface and underlying lithology. The same lithology forming different geomorphic units will have variable porosity and permeability, thereby causing changes in the potential of groundwater. Surface hydrological features like topography, drainage density, water bodies, etc., play an important role in groundwater replenishment [2]. For any developmental activity, both surface and groundwater sources are the main components depending on their quality and availability. The evaluation, development and management of an aquifer for water supply should proceed in stages. The aim of this study is to integrate VES with GIS to delineate geo-electric characteristics and evaluate groundwater potential of the Bullon group of sediments. In order to achieve this objective, the geo-electric parameters and overburden thickness in the area were determined from the VES data, and constructed earth model revealing geo-electric sequence /subsurface lithology in the area. For this research five boreholes were drilled and VES was carried out using the Schlumberger electrode configuration and the expanding procedure to map possible fractured assisted aquifer system in study area and to achieve the objectives. Data control was ensured by plotting the VES results on the field as the measurements were in progress. Unreasonable values that registered high standard deviation (SD) greater than unity were rejected and sounding repeated at the same spot several times until reasonable values were recorded. This method provides depth and thickness of various subsurface layers and their relative water yielding capacities [3].

\section{Description of the Study Area}

The historic village of Pepel (Figure 1) serves as a shipment port for Shandong Steel's iron ore, mined in Tonkolili District, northern region of Sierra Leone. Pepel village with a population of 1000 is relatively low-lying and one of several islands occurring on the Coastal Creek of Sierra Leone. It is located between latitudes $8^{\circ} 35^{\prime} 47^{\prime \prime} \mathrm{N}$ and longitudes $13^{\circ} 03^{\prime} 53^{\prime \prime} \mathrm{W}$. Although fishing is the main occupation of the people, the commencement of operations of Shandong Steel's Rail and Port facility has necessitated an influx of job-seekers from other parts of the country. The major land use is small-scale gardening which is practiced by older women. There are no surface water sources on the Island and groundwater appears to be the principal source of drinking water. The location of VES stations are shown in Figure 1. The climate of Pepel reflects the general climatic situation of the country, with a rainy season starting in May and ends in October, while dry conditions are experienced from November to April. Mean annual precipitation is 2980 $\mathrm{mm}$, with most of the rains falling in August $(767 \mathrm{~mm})$. January is the driest month, with a mean value of $2.41 \mathrm{~mm}$. There are no records of evapotranspiration, but, the latter seems to be much lower in line with the rest of the country.

\section{Geological Setting}

The Island is part of the Coastal Plain which is underlain by the Bullom Group (Figure 2) comprising of unconsolidated to poorlyconsolidated fluvial, estuarine, and marine sediments. The deposits extend up to $50 \mathrm{~km}$ inland and are found at heights of up to $40 \mathrm{~m}$ above present sea level. Although outcrops of the Bullom Group are poorly

*Corresponding author: Yaguba Jalloh, Department of Earth Resources Engineering, Kyushu University, Fukuoka, Japan, Tel: +8192642-2111; E-mail yjalloh2003@yahoo.com

Received October 27, 2017; Accepted November 03, 2017; Published November 10, 2017

Citation: Jalloh Y, Thomsa MO, Sasaki K (2017)Groundwater Assessment through an Integrated Approach Using GIS and Electrical Resistivity Technique: A Case Study from the Bullom Group of Sediments in Sierra Leone. J Environ Anal Toxicol 7: 523. doi: 10.4172/2161-0525.1000523

Copyright: (c) 2017 Jalloh Y, et al. This is an open-access article distributed under the terms of the Creative Commons Attribution License, which permits unrestricted use, distribution, and reproduction in any medium, provided the original author and source are credited. 
Citation: Jalloh Y, Thomsa MO, Sasaki K (2017)Groundwater Assessment through an Integrated Approach Using GIS and Electrical Resistivity Technique: A Case Study from the Bullom Group of Sediments in Sierra Leone. J Environ Anal Toxicol 7: 523. doi: 10.4172/2161-0525.1000523

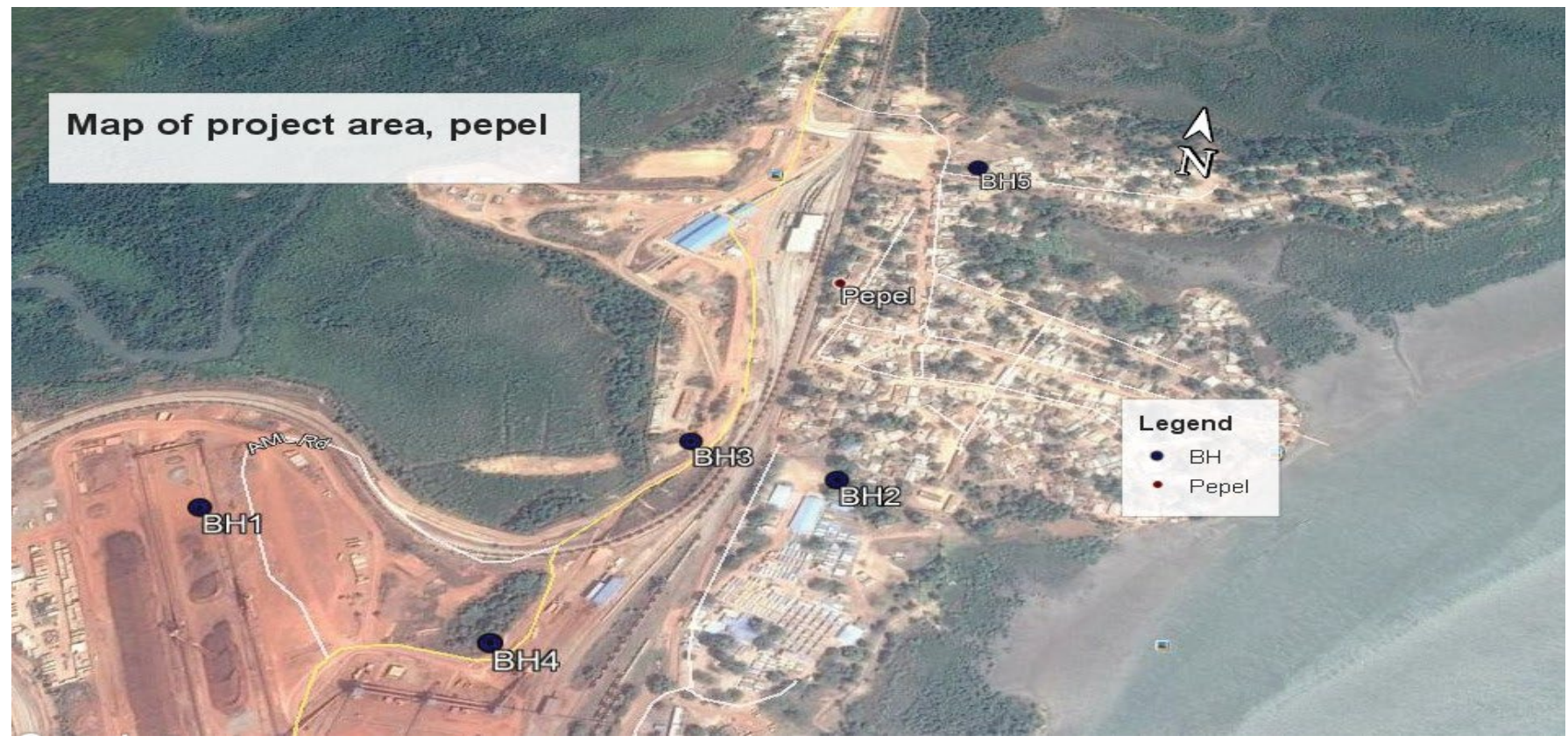

Figure 1: Map showing Pepel Island - the study area.

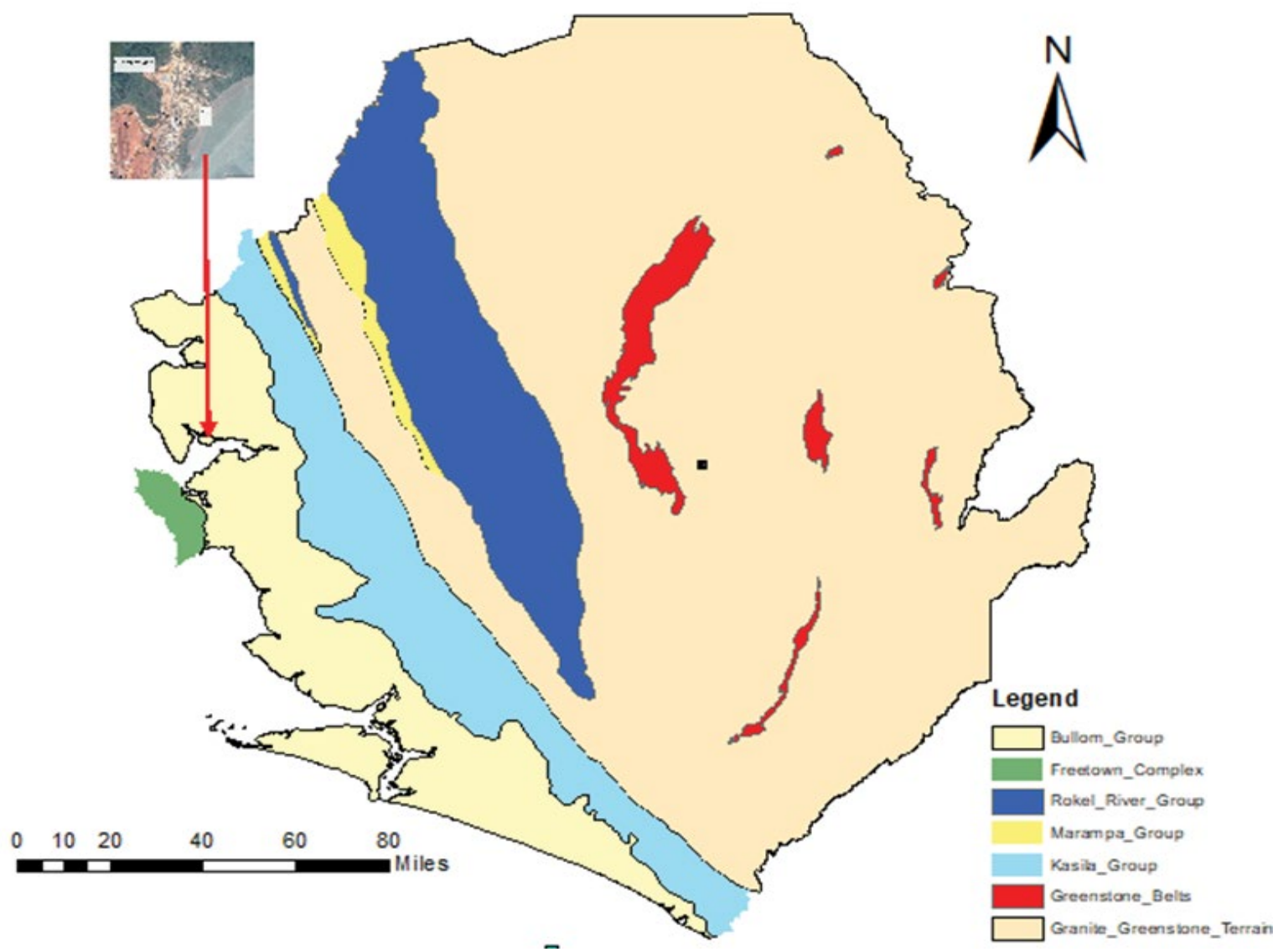

Figure 2: Geological map of Sierra Leone showing the Bullom Group. 
Citation: Jalloh Y, Thomsa MO, Sasaki K (2017)Groundwater Assessment through an Integrated Approach Using GIS and Electrical Resistivity Technique: A Case Study from the Bullom Group of Sediments in Sierra Leone. J Environ Anal Toxicol 7: 523. doi: 10.4172/2161-0525.1000523
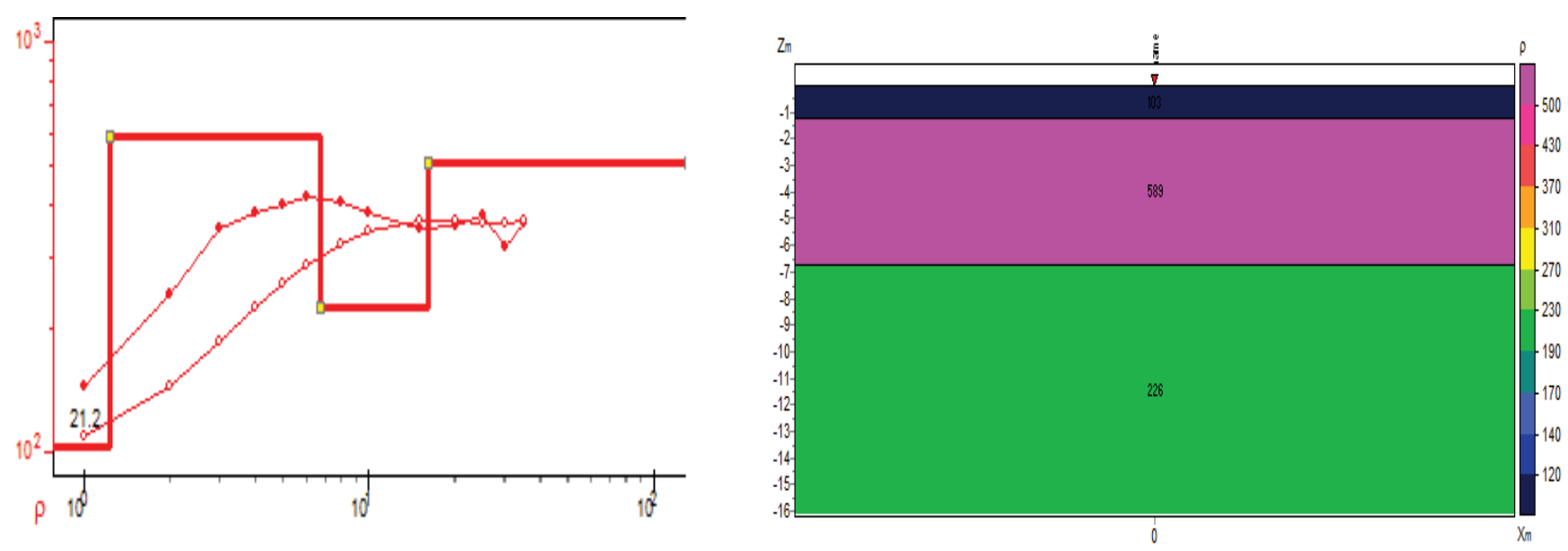

Figure 3: VES1 curve and VES1 pseudo-section.
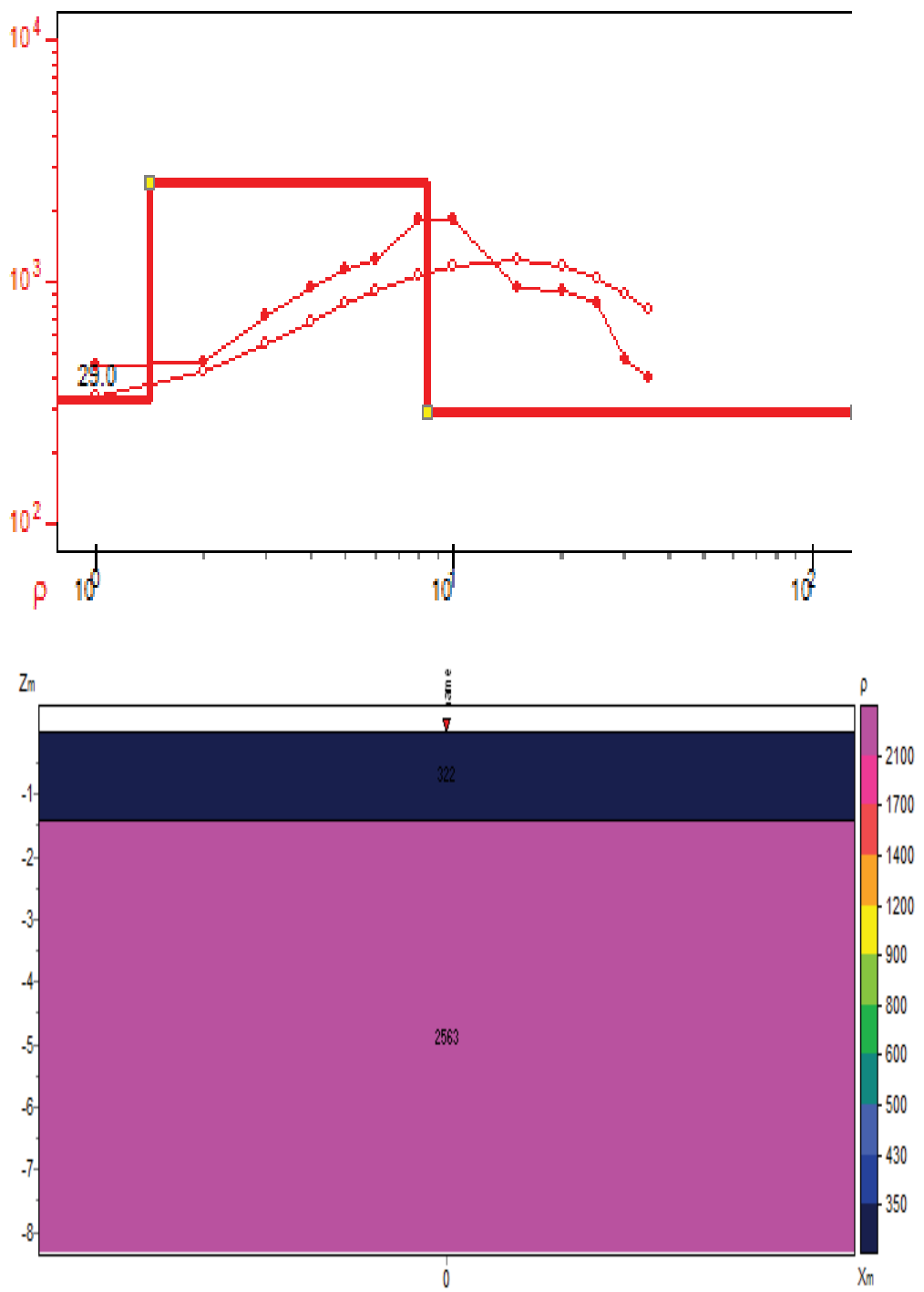

Figure 4: VES2 curve and VES2 pseudo-section. 
Citation: Jalloh Y, Thomsa MO, Sasaki K (2017)Groundwater Assessment through an Integrated Approach Using GIS and Electrical Resistivity Technique: A Case Study from the Bullom Group of Sediments in Sierra Leone. J Environ Anal Toxicol 7: 523. doi: 10.4172/2161-0525.1000523
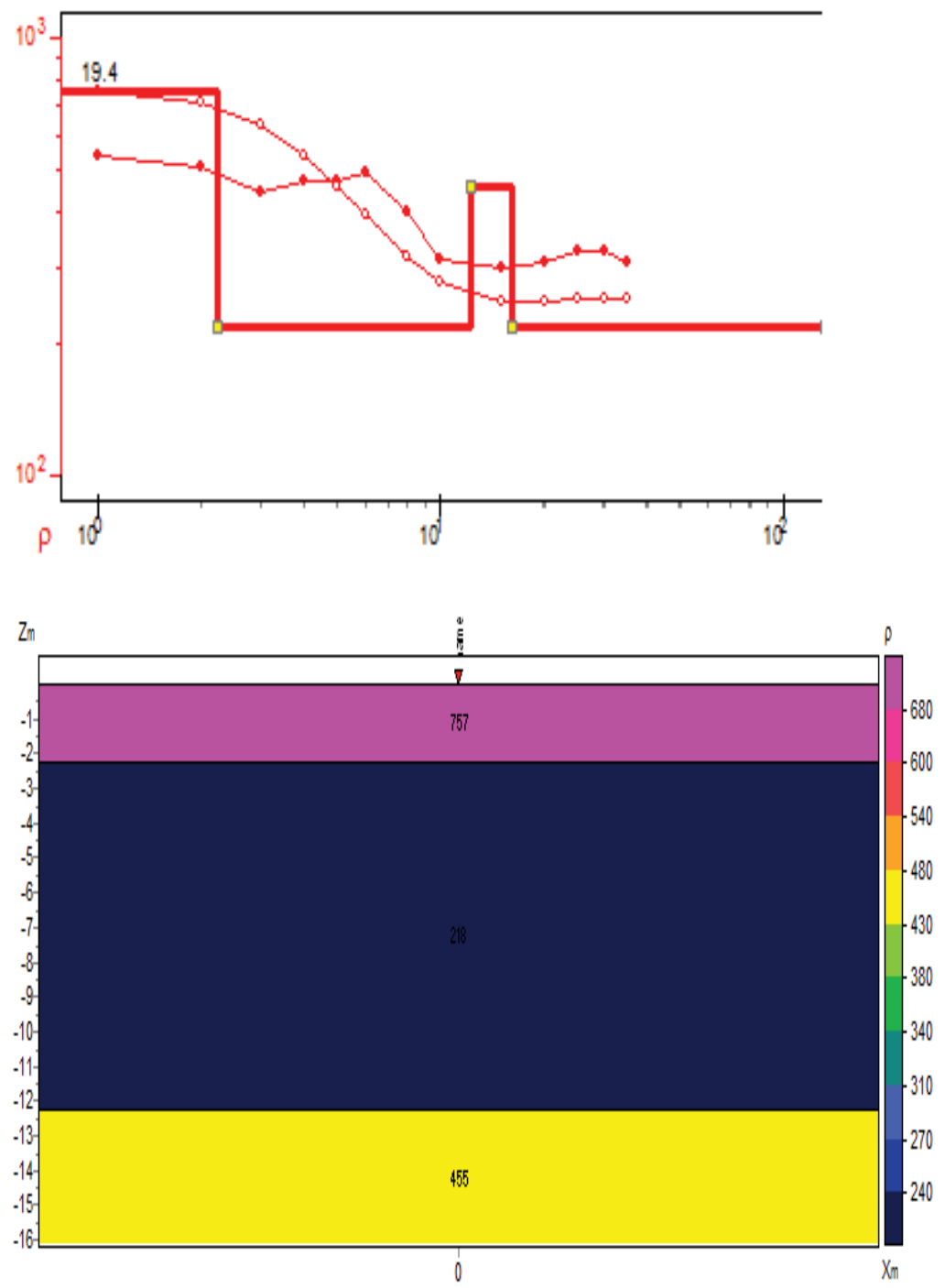

Figure 5: VES 3 curve and VES 3 pseudo-section

exposed on the Island, field observations supported by published data suggests a laterally variable sequence of poorly consolidated, near horizontal, often iron-stained gravels, sands, and clays with occasional intraformational laterites.

The sands are generally poorly sorted, sometimes graded, but rarely cross-bedded. Occasional grit beds, stringers of rounded quartz pebbles, and horizons of kaolinitic clay clasts are found in association with the sands. Also, within the sands are intraformational laterites, which often form puddingstone horizons. The clays are red, purple and white in color and are almost invariably kaolinitic.

\section{Hydrogeology}

There is a dearth of published data on the hydrogeology of the Bullom Group. However, recent drilling campaigns in areas underlain by these sediments have provided new evidence of its potential as a reliable source of water for drinking and other domestic use. Field observations on the Island corroborated by information from other sources suggest that the topmost layer in the sequence consists of medium to coarse iron-stained sandstone which overlies a clay layer of variable thickness that serves as an aquitard. The sediments are part of the Sand and Gravel Aquifer which is perhaps the most high-yielding of all the established aquifers in Sierra Leone.

A vertical section of a cliff face at Konakridee, a small fishing village west of the island suggests a multilayered sequence comprising both unconfined and confined aquifers. Groundwater occurs within poorly consolidated sands outcropping on the surface and between intervening layers of clay. Thus, semi-confined and confined conditions are likely in some places. Static water level measured in five boreholes drilled into the sand aquifer in the late dry season give a mean value of $10.6 \mathrm{~m}$. This value is expected to rise significantly at the end of the rainy season in October. Flow within the sand aquifer is intergranular attributable to poor consolidation of the sands. A Transmissivity of 3.34 $\mathrm{m} /$ day was determined in a borehole pumping at a rate of $130 \mathrm{~m} /$ day, for a maximum drawdown of $6.13 \mathrm{~m} \mathrm{[4]}$.

The area experiences high rainfall and moderate evapotranspiration, with a theoretical annual net surplus of water. The absence of legitimate 
Citation: Jalloh Y, Thomsa MO, Sasaki K (2017)Groundwater Assessment through an Integrated Approach Using GIS and Electrical Resistivity Technique: A Case Study from the Bullom Group of Sediments in Sierra Leone. J Environ Anal Toxicol 7: 523. doi: 10.4172/2161-0525.1000523
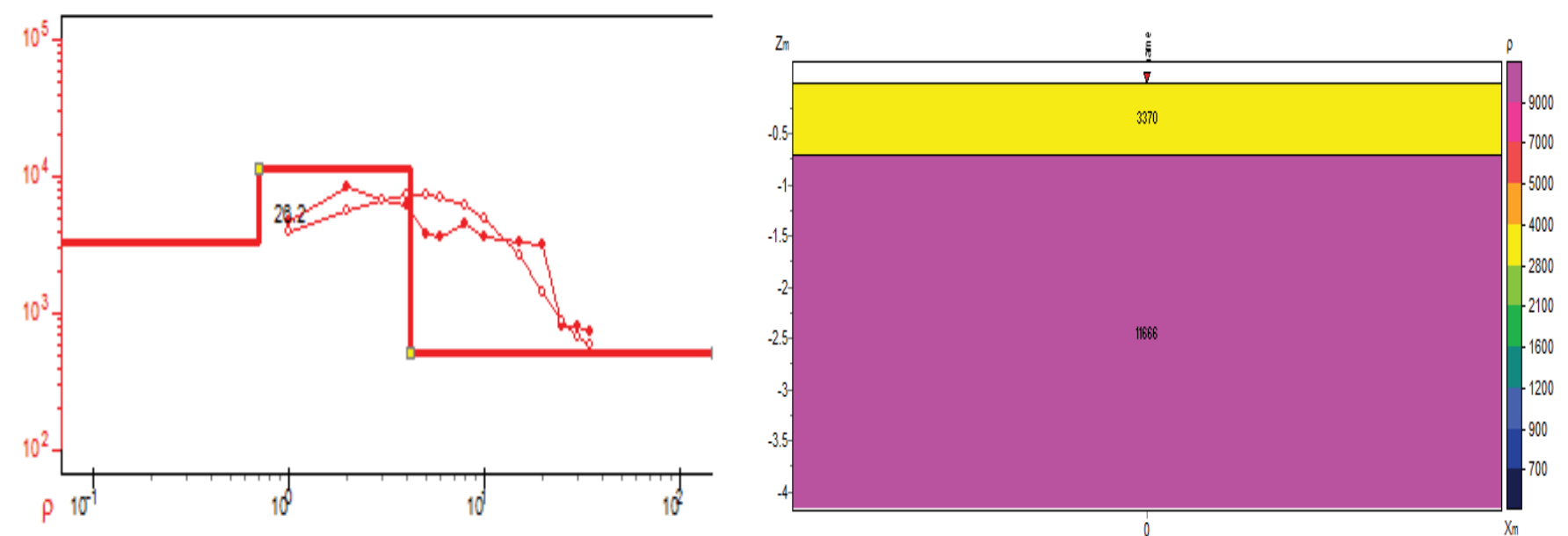

Figure 6: VES 4 curve and VES 4 pseudo-section.

\begin{tabular}{|c|c|c|c|c|}
\hline & No. & Apparent Resistivity (P) $(\Omega m)$ & Thickness (h) (m) & Depth (z) (m) \\
\hline \multirow{4}{*}{ VES1 } & 1 & 103.29 & 1.22 & $0 / 0$ \\
\hline & 2 & 589.26 & 5.48 & 1.22 \\
\hline & 3 & 226.14 & 9.49 & 6.71 \\
\hline & 4 & 506.38 & & 16.20 \\
\hline \multirow{3}{*}{ VES2 } & 1 & 321.71 & 1.41 & $0 / 0$ \\
\hline & 2 & 2562.98 & 6.95 & 1.41 \\
\hline & 3 & 285.86 & & 8.37 \\
\hline \multirow{4}{*}{ VES3 } & 1 & 756.98 & 2.24 & $0 / 0$ \\
\hline & 2 & 218.00 & 10.01 & 2.24 \\
\hline & 3 & 455.14 & 3.95 & 12.25 \\
\hline & 4 & 219.86 & & 16.20 \\
\hline \multirow{3}{*}{ VES4 } & 1 & 3369.71 & 0.71 & $0 / 0$ \\
\hline & 2 & 11666.20 & 3.48 & 0.71 \\
\hline & 3 & 513.93 & & 4.18 \\
\hline \multirow{3}{*}{ VES5 } & 1 & 608.21 & 1.58 & $0 / 0$ \\
\hline & 2 & 2059.68 & 7.77 & 1.58 \\
\hline & 3 & 464.50 & & 9.35 \\
\hline
\end{tabular}

Table 1: Apparent resistivity values and layer thicknesses as model output.

surface water sources clearly indicates that most of the rainfall goes into storage in the subsurface. By virtue of its location groundwater on the Island may be influenced by saline intrusion. Wells must therefore be located some reasonable distance from the sea and groundwater withdrawals should be well managed.

Water quality data obtained from pumped boreholes suggest that the ground waters are fresh with total dissolved solids content ranging between $41.3 \mathrm{mg} / \mathrm{l}$ and $94 \mathrm{mg} / \mathrm{l}$ [5]. The waters are relatively acidic with $\mathrm{pH}$ values ranging from 4.9 to 7.2 , with a mean of 5.9. Nitrate concentrations are slightly higher than the global standard [5], with a maximum concentration of $18 \mathrm{mg} / \mathrm{l}$.

\section{Materials and Methods}

\section{Earth resistivity survey}

An SAS 1000/4000 DZD 6A Multifunction Electrical meter was employed in the investigation to determine rock conductivity using the Vertical Electrical Sounding (VES) method. Five soundings were executed (VES1, VES2, VES3, VES4, and VES5) using the Schlumberger
Electrode Configuration. The Equation for apparent resistivity using the Schlumberger Configuration is given as:

$$
\rho_{\alpha}=\frac{\left(\frac{A B}{2}\right)^{2}-\left(\frac{M N}{2}\right)^{2}}{M N} \pi\left(\frac{V}{I}\right)
$$

Where, $\rho_{\alpha}=$ Apparent resistivity $(\Omega \mathrm{m})$; $\mathrm{I}=$ Current $(\mathrm{A}) ; \mathrm{AB}=$ Current electrode separation $(\mathrm{m}) ; \pi=3.142 ; \mathrm{MN}=$ Potential electrode separation $(\mathrm{m}) ; \mathrm{V}=$ Potential difference $(\mathrm{V})$ between $\mathrm{MN}$.

During the survey data control was ensured by plotting the VES results in the field as measurements were in progress. Questionable values that registered high standard deviation (sd) greater than unity were rejected and sounding repeated at the same spot several times until reasonable values were recorded. VES is the determination of vertical variation of resistivity through earth material, and is very reliable for groundwater exploration particularly in moderate terrain with less subsurface complexity as in the case of the Bullom group sand sediments [6-8]. 
Citation: Jalloh Y, Thomsa MO, Sasaki K (2017)Groundwater Assessment through an Integrated Approach Using GIS and Electrical Resistivity Technique: A Case Study from the Bullom Group of Sediments in Sierra Leone. J Environ Anal Toxicol 7: 523. doi: 10.4172/2161-0525.1000523
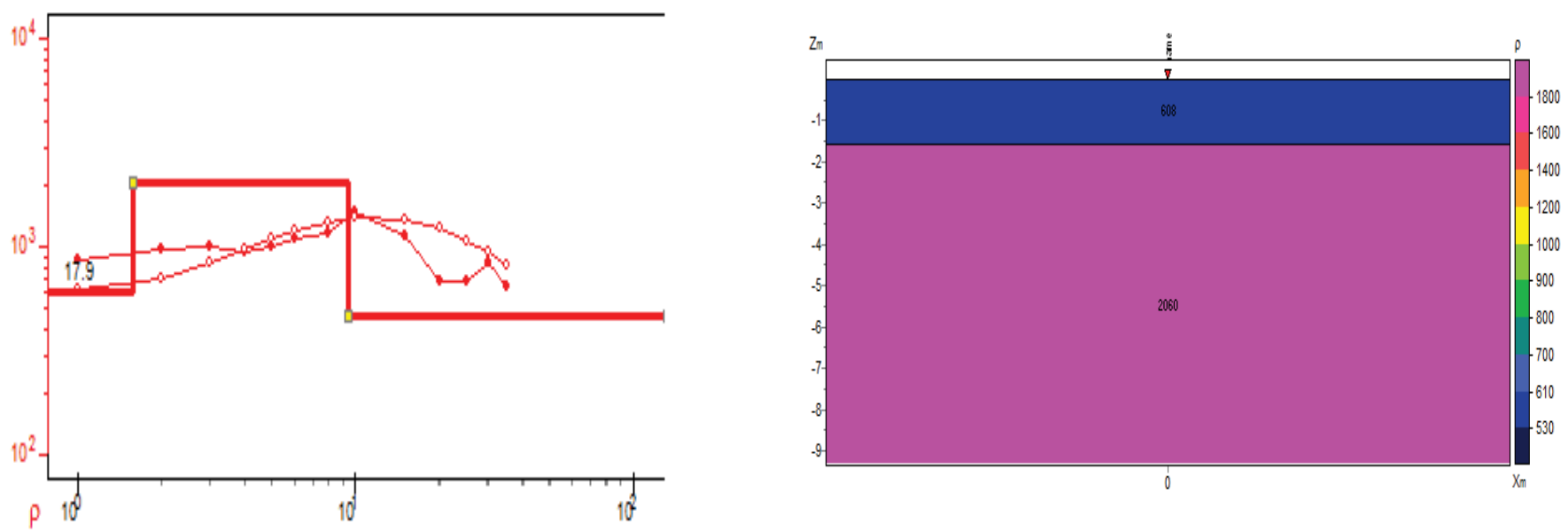

Figure 7: VES 5 curve and VES 5 pseudo-section.

\section{Pepel Groundwater Prospect Model}

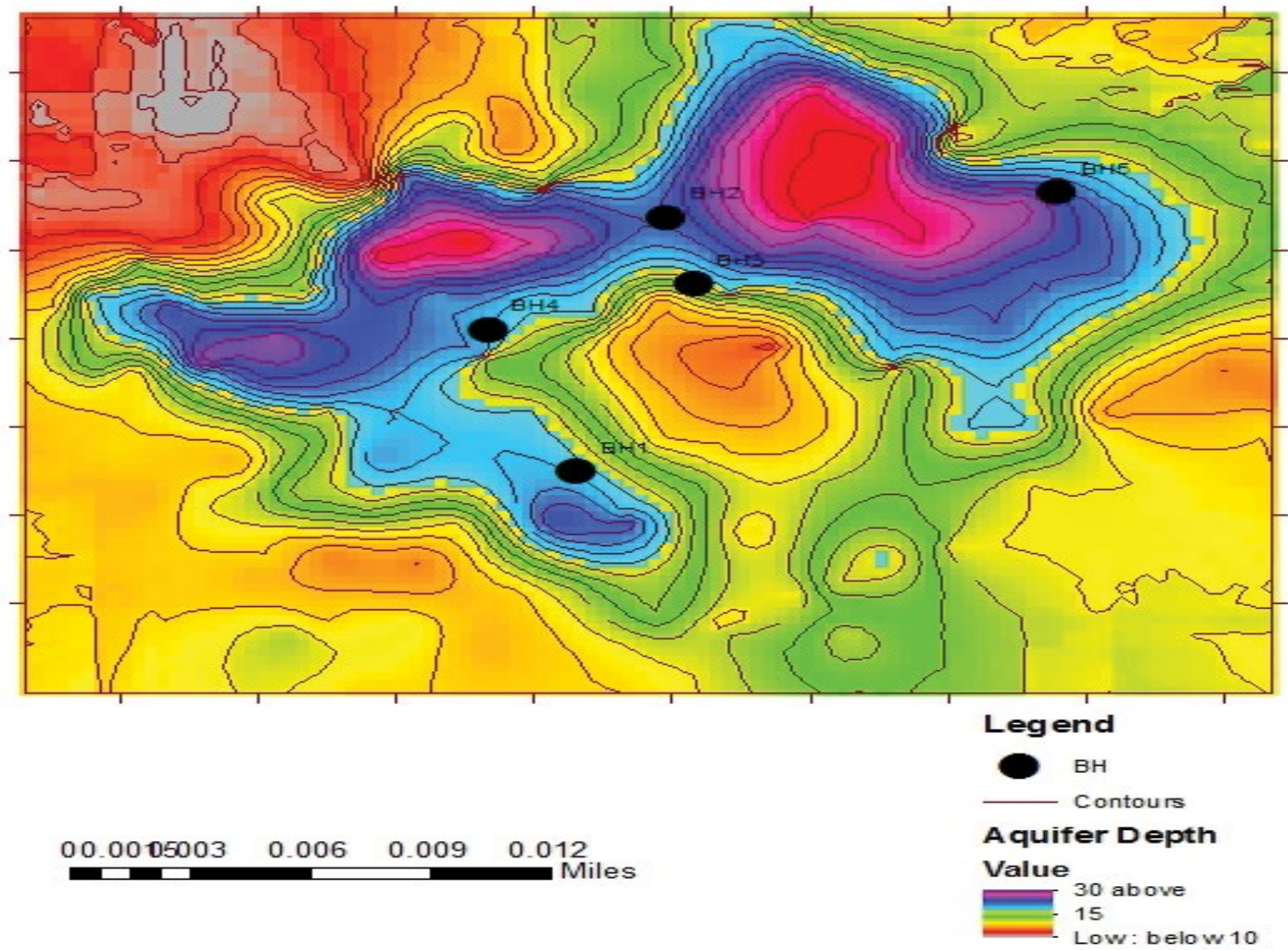

Figure 8: Average depth to groundwater map. 
Citation: Jalloh Y, Thomsa MO, Sasaki K (2017)Groundwater Assessment through an Integrated Approach Using GIS and Electrical Resistivity Technique: A Case Study from the Bullom Group of Sediments in Sierra Leone. J Environ Anal Toxicol 7: 523. doi: 10.4172/2161-0525.1000523

Page 7 of 7

\section{Results and Discussion}

\section{Interpretation of results}

The lithology from the five drilled boreholes shows the presence of four formations, comprising sandy/loamy topsoil, clay, fine sand and coarse sand, with groundwater being sourced from the third and fourth layers. However, the fourth layer consisting of sand/gravel is considered more prolific than the third layer. The geological information therefore serves as a guide in geophysical survey[x]. The VES field curves of the geoelectric data show the relation between the apparent resistivity and half the current electrode spacing as shown in the VES curves and sections (Figures 3-7).

The VES data for the five survey stations are presented in Table 1. Apparent Resistivity values ( $p$ obtained from the sounding were plotted against half the Current Electrode Spacing $(\mathrm{AB} / 2)$ using the computer code ZOND VESIP Version $\mathbf{5 . 1}$ and it shows the resistivity and the depth of the various formations. Three to Four geo-electric layers were found in the study area. The first is made up of sandy topsoil with a resistivity ranging between $103.29(\Omega \mathrm{m})$ in VES 1 and $3369.71(\Omega \mathrm{m})$ in VES 4 and a thickness of $1.22 \mathrm{~m}$ and $0.71 \mathrm{~m}$ respectively [8-10].

The second geo-electric layer consist of clayey sand which severs as aquitard for the study area and the resistivity of this layer ranges from $218.0(\Omega \mathrm{m})$ in VES 3 to $11666.20(\Omega \mathrm{m})$ in VES 4 with a thickness of $10.01 \mathrm{~m}$ and $3.48 \mathrm{~m}$ respectively.

The third geo-electric layer is a wet sand formation, drilling information reveals that this layer is water- bearing with groundwater found in three of the boreholes in this layer. Its resistivity ranges from 285.86 $(\Omega \mathrm{m})$ in VES2, $219.86(\Omega \mathrm{m})$ in VES 4 and $464.50(\Omega \mathrm{m})$ in VES 5 with a depth of $8.37 \mathrm{~m}, 4.18 \mathrm{~m}$ and $9.35 \mathrm{~m}$ respectively. The fourth geo-electric layer consist of coarse sandy gravel which is a confined aquifer this is evident at VES 1 and VES 3 and is therefore the source of portable water in the study area. Its resistivity ranges from $506.38(\Omega \mathrm{m})$ in VES1 and $219.86(\Omega \mathrm{m})$ in VES 3 with a depth of $16.20 \mathrm{~m}$ and $16.20 \mathrm{~m}$ respectively. The groundwater prospect model shown in Figure 8 shows the average depth of the various bore holes to groundwater level.

\section{Conclusions}

The results have revealed that the studied area is composed of the Bullon group of sediments and that the formation has undergone various degree of tectonic activities which control groundwater occurrence and accumulation but is prune to saline intrusion. Analyses also, have led to the understanding and delineation of the subsurface geological structure, depth to groundwater and aquifer properties such as aquifer vulnerability in the study area. Four geoelectric layers were identified viz a top sandy soil, a wet clay layer, and a fine-medium-coarse sand layer identified as the aquifer layer and the fourth sandy gravel layer as the confine aquifer which is the source of portable water in the study area. Depth to the aquifer ranges from $4.18 \mathrm{~m}$ in the vicinity of VES $4,8.37$ in the vicinity of VES $2,9.35 \mathrm{~m}$ in the vicinity of VES 5 . Both VES 1 and VES 3 have depth of $16.20 \mathrm{~m}$ each. The absence of legitimate surface water sources clearly indicates that most of the rainfall goes into storage in the subsurface which indicate that the groundwater potential in the area could be good to excellent.

\section{Recommendation}

Based on field observation, drilling information and analyses, it is recommended that:

(i) The maximum drilling depth within the studied area should not be less than $30 \mathrm{~m}$ below ground level to confirm the existence of aquifer system. However, depending on field conditions some areas could be less.

(ii)Also, water quality test should be carried out on the borehole water samples from completed well to ascertain that it is drinkable.

\section{Acknowledgements}

The authors wish to acknowledge the support provided by the Japan Society for the Promotion of Science (JSPS) for the RONPAKU funding.

\section{References}

1. Oyedele EA, Olayinka Al (2012) Statistical evaluation of groundwater potentia of Ado-Ekiti, southwest Nigeria. Transnational Journal of Science and Technology 2: 110-127.

2. Shahid S, Nath S, Roy J (2000) Groundwater potential modelling in a soft rock area using a GIS. International Journal of Remote Sensing 21: 1919-1924.

3. Nwachukwu MA, Aslan A, Nwachukwu MI (2013) Application of Geographic Information System (GIS) in sustainable groundwater development, Imo River Basin Nigeria. International Journal of Water Resources and Environmental Engineering 5: 310-320.

4. Sierra Leone Water Company SAWACO (2017).

5. African Minerals Ltd. (2011) Available from: http://www.africanminerals.com/ system/files/press/AfricanMinerals2011WEB.pdf

6. Tucker ME, Reid PC (1973) The sedimentology and context of Late Ordovician glacial marine sediments from Sierra Leone, West Africa. Palaeogeography, Palaeoclimatology, Palaeoecology 13: 289-307.

7. Shishaye HA, Abdi S (2016) Groundwater Exploration for Water Well Site Locations Using Geophysical Survey Methods. Hydrol Current Res 7: 2.

8. Anomohanran $\mathrm{O}$ (2015) Hydrogeophysical and hydrogeological investigations of groundwater resources in Delta Central, Nigeria. Journal of Taibah University for Science 9: 57-68.

9. VenkataRao G, Kalpana P, Rao RS (2014) Groundwater investigation using geophysical methods-a case study of Pydibhimavaram Industrial area. International Journal of Research in Engineering and Technology 3: 13-17.

10. Area A (2014) International Journal of Research in Engineering and Technology 3: $13-17$. 